\section{The complete rotary file system}

RACE EVO is the ultimate evolution of the popular and proven RaCe rotary system. Boasting 40\% more flexibility, 50\% higher cutting efficiency and 2.8 times more resistance to fatigue than its predecessor, RACE EVO instruments are engineered for high performance and smooth progression.

Highly dependable original $\mathrm{RaCe}$ features combined with proprietary heat treatment and higher rotation speed capability make RACE EVO instruments even safer, easier to control and more efficient than ever before.

RACE EVO specific heat treatment provides unprecedented mechanical properties, which in turn allow higher speed for quicker and more comfortable treatment for patients.

\section{Transform your treatments}

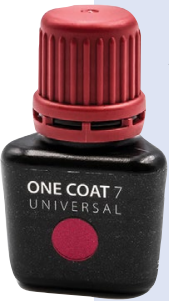

For treatment that is minimal, yet transformative, COLTENE supplies restorative materials of high quality that enable ungraded dentistry.

People want a better smile, but they want it to be subtle, and they want the result to endure.

A tall order? Not with

COLTENE, with solutions including:

- One Coat 7 Universal, a light-cured, one-component bonding agent

- BRILLIANT EverGlow universal composite to mimic the appearance of the tooth

- BRILLIANT Componeer prefabricated veneers for aesthetic anterior restorations.

Visit the website to find out more to be ready for the boom in dentistry, COLTENE can support you to achieve exceptional results. For more on COLTENE, visit www.coltene.com, email info.uk@coltene.com or call 0800 2545115.

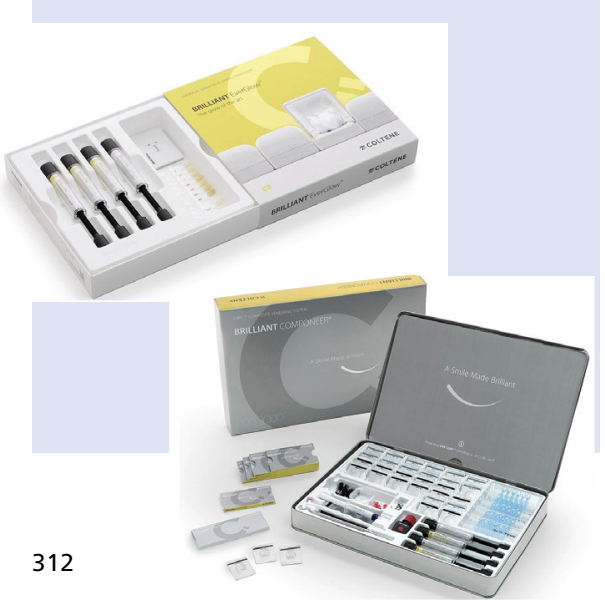

Exclusive heat treatment combined with legacy $\mathrm{RaCe}$ features provide the perfect combination of strength, durability and control. With unmatched resistance to cyclic fatigue, optimised yet non-intrusive cutting efficiency and a low screwing effect, RACE EVO is designed to be safe.

The RaCe design and over 20 years of trusted performance associated with higher speed bring improved efficiency with a familiar feel to RACE EVO instruments.

RACE EVO allows you to choose your therapeutic approach. Our full selection of instruments lets you successfully treat various canal anatomies.

RACE EVO offers two core sequences with the highest optimaluse range: RACE EVO $4 \%$ and RACE EVO 6\% complete with one glide path and two shaping instruments. In addition, the flexibility offered by the choice of two larger instruments ensures each treatment is bespoke to the patient.

For further information on RACE EVO contact Schottlander on freephone 080097000 79, email: sales@ schottlander.co.uk or visit www.schottlander.com.

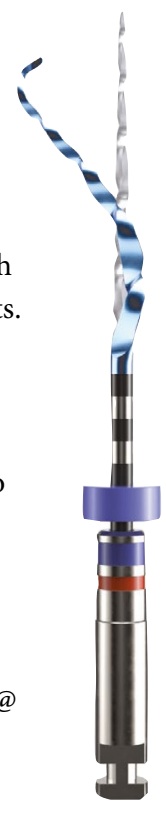

\title{
The perfect choice for all your financial needs
}

Whenever you need financial advice, it pays to choose a company that has years of experience.

Widely regarded as the leading firm of Independent Financial Advisers (IFAs) in the country, money4dentists is the perfect choice for all of your financial needs.

The team only work with dentists, meaning that they have a unique industry insight. Plus, the award-winning team can help you to achieve a vast array of goals, whether this is sorting your taxes, investing in a new practice, getting your assets in order before retirement and much, much more.

To find out more, contact the team today.

For more information call 0845345 5060, email info@money4dentists.com or visit www.money4dentists.com.

\section{When should you use CBCT for dental implants?}

Dr Andrew Shelley (pictured) is a Specialist in Prosthodontics, a Fellow of the Royal College of Surgeons of Edinburgh and of England, and an Honorary Research Fellow of the University of Manchester. With a special interest in imaging prior to dental implant placement and the author of several published papers on the topic, he shared his expertise as part of an ADI Webinar, available free for ADI members.

His session, entitled 'CBCT, Do You Always Need It?', explored the reasons to use or avoid CBCT imaging when approaching dental implants. He offered practical hints and tips to help clinicians be more consistent in their decision-making process.

He adds: 'I also presented findings of a systematic review of the available literature. I also explored the results of a study we set up, with colleagues placing dental implants in

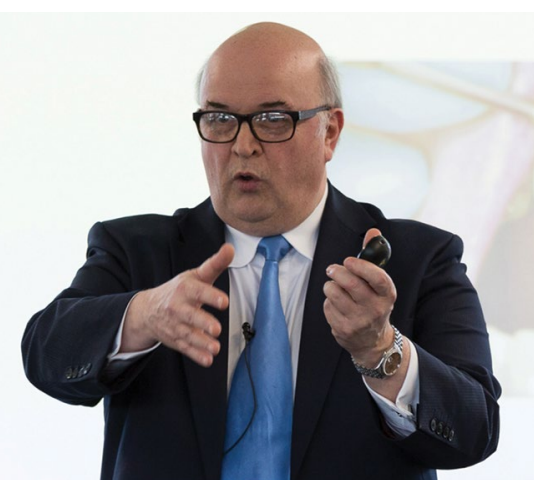

the mandible of phantom heads using either 2D or 3D images for treatment planning.

This is just one membership benefit offered through the ADI - find out more today.

ADI members can access ADI Webinars for free. For more information about the ADI, or to join, visit the website www.adi. org.uk. 